\title{
Simulation in surgical education: mentors' point of view
}

\author{
Francisco Schlottmann \\ Department of Surgery, Hospital Alemán of Buenos Aires, Buenos Aires, Argentina \\ Correspondence to: Francisco Schlottmann, MD, MPH. Department of Surgery, Hospital Alemán of Buenos Aires, Buenos Aires, Argentina. \\ Email: fschlottmann@hotmail.com.
}

\begin{abstract}
Simulation allows surgical trainees to practice in a safe and standardized setting. Reduction of working hours, financial need of efficiency, and ethical dilemmas over patient's safety have motivated the development of surgical simulation. Currently, a wide variety of surgical simulators are available with a broad range from simple and economic models to highly sophisticated and expensive ones. Some of them are used to train basic surgical skills, and others offer realism and opportunities to train entire surgical procedures. Acquisition of surgical skills and improvement of intraoperative performance are main advantages associated with simulation. High-fidelity simulated operating rooms also allow for training teamwork technical and non-technical skills such as response to intraoperative crisis scenarios or communication skills among team members. In addition, simulation is very useful for practicing surgeons who want to embrace new technologies in their practice. On the other hand, costs, limited manpower resources, and lack of standardized simulation curricula are significant challenges of surgical simulation. While in some countries surgical simulation is already well-established, in others simulation is not yet formally included in the training curricula. As simulation is a key component of surgical education, further efforts are needed to formally incorporate simulation in every surgical residency program.
\end{abstract}

Keywords: Surgical simulation; education; training; surgical residents

Received: 01 June 2021; Accepted: 16 June 2021; Published: 30 September 2021.

doi: $10.21037 /$ asj-21-40

View this article at: https://dx.doi.org/10.21037/asj-21-40

\section{Introduction}

Simulation allows surgical trainees to practice in a safe and standardized setting. Several changes in our health care system have motivated the development of surgical simulation: reduction of working hours (80-hour resident work week), financial need of efficiency (necessity of shorter operative times and shorter admission times), and ethical dilemmas over patient's safety (1-3).

Currently, a wide variety of surgical simulators are available (broad range from simple and economic models to highly sophisticated and expensive ones): box-lap trainers, virtual-reality platforms, 3D printed artificial models, animal-based tissue blocks, cadavers, and live animals among others (4-7). Some of them are used to train basic surgical skills, and others offer realism and opportunities to train entire surgical procedures (Figures 1 and 2).

In some countries like the United States, surgical simulation is already well-established. In fact, the Accreditation Council for Graduate Medical Education (ACGME) has determined that surgical training programs in the US must ensure the availability of simulation which "must address acquisition and maintenance of skills with a competency-based method of evaluation" (8). In other countries, however, simulation is not yet formally included in the training curricula.

In this manuscript, I aimed to describe advantages, disadvantages and potential challenges of surgical simulation based on my experience as a surgical educator.

\section{Advantages of surgical simulation}

I believe surgical simulation has several strengths that should be highlighted:

* Acquisition of surgical skills: It is already proven that surgical skills can be adequately acquired 


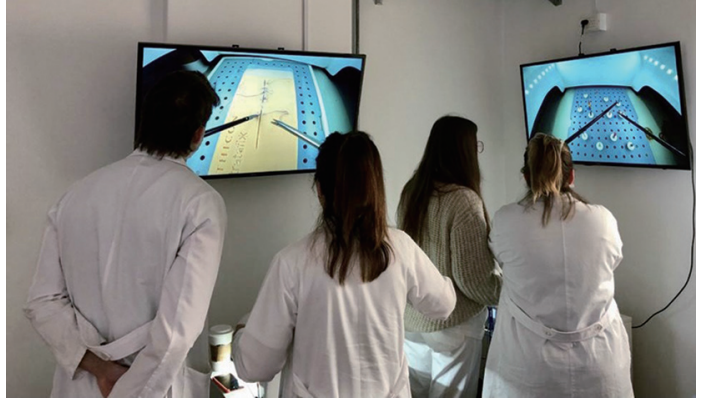

Figure 1 Box lap trainers allow for training basic laparoscopic skills.

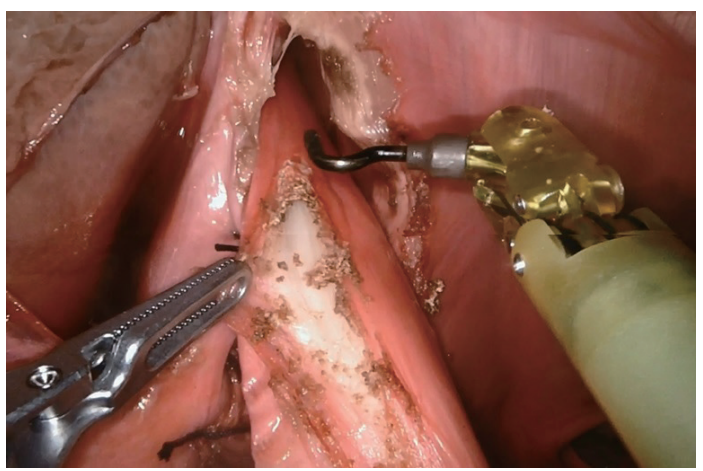

Figure 2 Entire surgical procedures can be simulated with the use of perfused animal tissue blocks (Robotic Heller Myotomy).

and mastered with the use of simulation. For example, a previous randomized trial showed that trainees undergoing simulation for laparoscopic cholecystectomy were 9 times less likely to fail to make progress and 5 times less likely to injure the gallbladder or burn nontarget tissues, as compared to those without simulation (9). A recent study also demonstrated that robotic surgery simulation increases confidence levels among senior residents for port placement, docking process, suturing, use of energy devices, and use of staplers (10).

* Improvement of intraoperative performance and reduced operative times: Simulation training before performing a "real case" in the operating room helps reducing operative time. From my experience, the difference is clearly noted in surgical steps such as laparoscopic suturing, in which residents with hours of simulation perform better and faster. In fact, a randomized trial proved that training on either a virtual reality simulator or on a box trainer significantly decreases the learning curve necessary to learn laparoscopic suturing (11). In addition, a systematic review analyzing 10 randomized trials and one nonrandomized comparative study confirmed that most skills acquired by simulationbased training are transferable to the operative setting (12).

* Improvement of team-based surgical skills: Highfidelity simulated operating rooms currently allow for training teamwork technical and nontechnical skills (response to intraoperative crisis scenarios, team performance, situation awareness, decision making, communication skills among team members, etc.) (13).

* Adoption of novel procedures / new devices: Surgery is a rapidly evolving field and novel devices and procedures are constantly available. Simulation is very useful for practicing surgeons who want to embrace new technologies in their practice.

* Training during a pandemic: Although COVID-19 pandemic has affected almost every aspect of the healthcare system, surgical specialties have been specially troubled by a decline in their activity. A recent study showed how the quarantine associated with the pandemic provoked a decreased in the number of procedures performed by surgical residents (14). Increased hours of surgical simulation can potentially help to mitigate the lack of clinical training during pandemic times (which unfortunately may occur again in the future).

\section{Disadvantages and challenges of surgical simulation}

Surgical simulation is also associated with potential disadvantages or challenges:

* Real world surgical training is irreplaceable: Although simulation indeed helps obtaining proficiency of surgical skills, some aspects of real operations cannot be taught in a simulation laboratory (e.g., real tissue feeling, live human anatomy, stressed generated by intraoperative complications). In other words, simulation helps but it has certain educational limitations. Educators should be aware of these limitations, exploit all the learning tools that simulation training provides and finally teach and supervise trainees in real cases.

* Costs: The cost of creating a simulation laboratory 
can be as high as $\$ 1$ million and maintaining personnel, materials, and equipment can represent expenses of up to $\$ 55,000 /$ year (15). Therefore, costs are an undoubtedly limitation for the adoption of surgical simulation in low- and middleincome countries.

* Manpower resources: Besides the financial burden of simulation, the limited availability of faculty to teach outside the operating room is another barrier. Well-trained trainers with dedicated time for simulation are critical for the success of training activities.

* Lack of standardized training curricula: Although there are some validated programs of education and assessment such as the fundamentals of laparoscopic surgery (FLS) (16), we still lack comprehensive simulation curricula addressing all the components of surgical competency (cognitive aspects, technical skills and non-technical skills).

\section{Simulation in surgical education: yes or no? If yes, how?}

Interestingly, many current practicing surgeons did not have simulation activities during their training. In fact, I did not have the opportunity to train in a simulation laboratory as a trainee. However, we should not be proud about that. It would be inconceivable to allow a pilot to fly a plane with passengers without prior training in simulators. Similar to the aviation industry, there are now high-fidelity surgical simulators. Therefore, surgical simulation should be mandatory throughout the residency in order for trainees to safely perform on patients.

Simulation must be formally incorporated in the surgical residency curriculum in order to be an effective educational tool. Episodic and opportunistic simulation activities on a voluntary basis ("gym modality") should be discouraged. Residents should rather have protected time for simulation activities with instructors guiding and teaching them.

As expenditures may limit the use of simulation in some institutions, development of low-cost and useful surgical simulators is still needed. Resources should also be properly administrated; while junior trainees can reliably learn basic skills with simple low fidelity models, sophisticated simulators with higher fidelity are more important for senior trainees learning complex procedures. Finally, return on investment analyses demonstrating that potential cost savings from shorter operative times, decreased intraoperative complications, and better handling of surgical equipment might outweigh the high expenses associated with simulation are needed. These types of analyses might help convincing hospital administrators and policymakers that simulation is critical.

\section{Conclusions}

Simulation is a key component of surgical education that should be formally integrated in every surgical residency curriculum. Well-trained trainers with dedicated time for simulation are critical for the success of this educational tool. In addition, further efforts are needed to develop standardized simulation programs with validated simulators.

\section{Acknowledgments}

Funding: None.

\section{Footnote}

Provenance and Peer Review: This article was commissioned by the Guest Editors (Fernando A. M. Herbella and Volha Raznitsyna) for the series "Modern Challenges in the Education of Young Surgeons: the Two Sides of the Coin" published in AME Surgical fournal. The article has undergone external peer review.

Conflicts of Interest: The author has completed the ICMJE uniform disclosure form (available at https://asj.amegroups. com/article/view/10.21037/asj-21-40/coif). The series "Modern Challenges in the Education of Young Surgeons: the Two Sides of the Coin" was commissioned by the editorial office without any funding or sponsorship. The author has no other conflicts of interest to declare.

Ethical Statement: The author is accountable for all aspects of the work in ensuring that questions related to the accuracy or integrity of any part of the work are appropriately investigated and resolved.

Open Access Statement: This is an Open Access article distributed in accordance with the Creative Commons Attribution-NonCommercial-NoDerivs 4.0 International License (CC BY-NC-ND 4.0), which permits the noncommercial replication and distribution of the article with the strict proviso that no changes or edits are made and the original work is properly cited (including links to both the 
formal publication through the relevant DOI and the license). See: https://creativecommons.org/licenses/by-nc-nd/4.0/.

\section{References}

1. Aggarwal R, Mytton OT, Derbrew M, et al. Training and simulation for patient safety. Qual Saf Health Care 2010;19 Suppl 2:i34-43.

2. Reznick RK, MacRae H. Teaching surgical skills--changes in the wind. N Engl J Med 2006;355:2664-9.

3. Evgeniou E, Loizou P. Simulation-based surgical education. ANZ J Surg 2013;83:619-23.

4. Sutherland LM, Middleton PF, Anthony A, et al. Surgical simulation: a systematic review. Ann Surg 2006;243:291-300.

5. ASGE Technology Committee; Goodman AJ, Melson J, et al. Endoscopic simulators. Gastrointest Endosc 2019;90:1-12.

6. Lemarteleur V, Peycelon M, Sablayrolles JL, et al. Realization of Open Software Chain for 3D Modeling and Printing of Organs in Simulation Centers: Example of Renal Pelvis Reconstruction. J Surg Educ 2021;78:232-44.

7. Schlottmann F, Patti MG. Novel simulator for robotic surgery. J Robot Surg 2017;11:463-5.

8. ACGME Program requirements for Graduate Medical Education in General surgery. Available online: https:// www.acgme.org/Portals/0/PFAssets/ProgramRequirements 440_GeneralSurgery_2019_TCC.pdf.

doi: 10.21037/asj-21-40

Cite this article as: Schlottmann F. Simulation in surgical education: mentors' point of view. AME Surg J 2021;1:15.
9. Seymour NE, Gallagher AG, Roman SA, et al. Virtual reality training improves operating room performance: results of a randomized, double-blinded study. Ann Surg 2002;236:458-63; discussion 463-4.

10. Schlottmann F, Long JM, Brown S, et al. Low confidence levels with the robotic platform among senior surgical residents: simulation training is needed. J Robot Surg 2019;13:155-8.

11. Orzech N, Palter VN, Reznick RK, et al. A comparison of 2 ex vivo training curricula for advanced laparoscopic skills: a randomized controlled trial. Ann Surg 2012;255:833-9.

12. Sturm LP, Windsor JA, Cosman PH, et al. A systematic review of skills transfer after surgical simulation training. Ann Surg 2008;248:166-79.

13. Gettman MT, Pereira CW, Lipsky K, et al. Use of high fidelity operating room simulation to assess and teach communication, teamwork and laparoscopic skills: initial experience. J Urol 2009;181:1289-96.

14. Angeramo CA, Schlottmann F. Impact of COVID-19 on surgical residency programs: A glass half-full reflection. Int J Surg 2021;89:105958.

15. Harrington DT, Roye GD, Ryder BA, et al. A time-cost analysis of teaching a laparoscopic entero-enterostomy. J Surg Educ 2007;64:342-5.

16. Peters JH, Fried GM, Swanstrom LL, et al. Development and validation of a comprehensive program of education and assessment of the basic fundamentals of laparoscopic surgery. Surgery 2004;135:21-7. 